\title{
Research of Multi-service Fulfillment of Rail Train-Ground Communication Based on TD-LTE Technology
}

\author{
Wu Lei and Yue Xingzuo* \\ Wuhan Institute of Shipbuilding Technology \\ 89370742@qq.com
}

Keywords: TD-LTE; Train-ground communication; Multi-service fulfillment; Qos

\begin{abstract}
In order to study the feasibility of using TD-LTE technology to carry out rail transit integrated service bearer, analyze the bearer demand of vehicle-to-ground communication service and the technical characteristics of TD-LTE, this paper proposes a TD-LTE vehicle land suitable for rail transit integrated service bearer. The wireless technology solution was tested and verified on the first phase of Zhengzhou Rail Transit Line 1. The results show that TD-LTE technology can meet the needs of rail transit integrated service bearer.
\end{abstract}

\section{Introduction}

With the acceleration of urbanization in China, most of the floating population has flooded into cities, and the number of private cars has grown rapidly. This has put tremendous pressure on urban traffic, traffic congestion and air pollution have become increasingly serious, seriously affecting the city's economic development and people's daily lives. Therefore, all major cities are actively developing large-capacity, fast, on-time and safe urban rail transit systems.

As the important part of ensuring the safe operation of urban rail transit, the wireless communication of the vehicle and the vehicle carries the CBTCS (Communication Based Train Control System), the train operation monitoring system, the CCTV (Closed Circuit Television), and the passengers. Information system (PIS, Passenger Information System) and other information transmission. It can be described as the nerve center of the rail transit system.

At present, the wireless communication of vehicles and land in urban rail transit mainly adopts wireless local area network (WLAN) technology. Engineering practice has proved that although WLAN can meet the requirements of current wireless communication availability, reliability, security, etc., it has many limitations, such as:

(1) The speed of operation is limited. Simulation and research show that the bit error rate will increase sharply when the train speed exceeds $120 \mathrm{~km} / \mathrm{h}$.

(2) The coverage distance is short and the link design is complex. It is necessary to install a large number of APs and attached equipment along the line to reduce the reliability and availability of the system, and frequent inter-AP handover, which affects the communication quality ${ }^{[1]}$;

(3) Wireless interference is serious, WLAN works in the open frequency band, and is easily interfered by other electronic devices such as portable WIFI, which affects the safe operation of rail transit [2];

(4) When multiple services are concurrency, they cannot be used according to the priority. The actual bandwidth of the high-priority service cannot be guaranteed.

In order to improve the safety and service level of urban rail transit operations, it is urgent to integrate the vehicle-to-ground wireless communication production service bearing requirements and establish a vehicle-to-ground communication system based on the urban rail transit-specific wireless frequency band. This enables CBTC information, train status monitoring information, CCTV, and PIS (including emergency text) to be transmitted in a timely and accurate manner, providing strong support 
for the safe and efficient operation of the urban rail transit system.

\section{Vehicle and Land Communication Service Carrying Requirements}

\section{CBTC System's Application Requirements}

The CBTC system completes the control function for safe driving of the vehicle. It needs to cover the main line of urban rail transit (including return line, tie line), access section/field line, section/field throat area, section/field garage, and test line. The system requires independent dual-network redundant physical communication channel design, and encrypts the transmission data to ensure communication security. The test line part needs to be isolated from other parts. The transmission rate of the entire line per train is not less than $200 \mathrm{kbp}_{\mathrm{S}}, 100 \mathrm{kbp}_{\mathrm{S}}$ for uplink and downlink ${ }^{[3]}$, the bit error rate is less than or equal to $10^{-6}$, and the handover time and transmission delay are within $150 \mathrm{~ms}$. At least one network at the same time in the dual network is uninterrupted.

\section{Application Requirements of the Train Operation Condition Monitoring System}

The train operation condition monitoring system is used to ensure the safe operation of key equipment systems during vehicle operation, including information collection, information transmission, information display, information processing and analysis, and information release ${ }^{[5]}$.

The train operation status monitoring system information transmission is one-way transmission, and the information collection quantity has 1500 switching quantities, each 1 bit; 500 analog quantities, each 2 bytes. The amount of information collected at one time is $9.5 \mathrm{kbits}$, and the acquisition period is $300 \mathrm{~ms}$ - times, calculated at 4 times per second, and the transmission rate is $38 \mathrm{kbps}$. Considering a certain amount of information transmission margin, a total transmission rate of $100 \mathrm{khPs}$ is required. The train transmission status monitoring system has a vehicle-to-ground information transmission delay requirement of less than $150 \mathrm{~ms}$ and a packet loss rate requirement of less than $1 \%$.

\section{Application Requirements of the CCTV System}

The car CCTV video surveillance image backhaul uploads the car video surveillance image to the control center. Under normal circumstances, the entire line of the main line needs to upload 2 channels of room monitoring image information to the center. The upstream bandwidth requirement for the in-vehicle CCTV service is 2 x $2 \mathrm{Mbps}=4 \mathrm{Mbps}^{[5]}$. When the train is parked at the vehicle base, the center can simultaneously capture the video information of the 4 passenger room surveillance images, and the uplink bandwidth requirement is $4 \times 1 \mathrm{Mbps}=4 \mathrm{Mbps}$. The CCTV system has a transmission delay requirement of less than $300 \mathrm{~ms}$ and a delay jitter requirement of less than $100 \mathrm{~ms}$.

\section{Application Requirements of the PIS System}

The PIS system (including emergency text) needs to display the broadcast programs issued by the broadcast control center, such as emergency text information, driving information, news broadcasts, travel guides, transfer information, online advertisements, etc., on the vehicle PIS display ${ }^{[6]}$.

The PIS image uses the standard definition image quality M, and the carrier information bandwidth per train is $2 \mathrm{Mbps}$ downstream. Under normal circumstances, there are two trains in the wireless cell, and the bandwidth requirement for PIS image playback is 2 x 2 Mbps $=4$ Mbps (downlink information). When there are conditions, the high-definition (1 $080 \mathrm{P})$ image quality MM is used to set the traffic channel bandwidth, and the bandwidth of each image is requested to be 4-6 Mbps downstream. The emergency text message bandwidth requirement is $10 \mathrm{~kb}$. The PIS system requires a transmission delay of less than $300 \mathrm{~ms}$ and a delay jitter requirement of less than $100 \mathrm{~ms}$.

\section{Summary of the Wireless Communication Needs of the Car}

The summary of wireless communication requirements for urban rail transit production business vehicles is shown in Table 1. 
Table 1 Wireless Communication Needs of Rains

\begin{tabular}{|c|c|c|c|c|c|c|c|}
\hline No & $\begin{array}{l}\text { Carrying } \\
\text { business }\end{array}$ & Upper line & Lower line & $\begin{array}{c}\text { Handover } \\
\text { delay/ms }\end{array}$ & $\begin{array}{c}\text { Transmissi } \\
\text { on delay / } \\
\text { ms }\end{array}$ & Coverage interval & $\begin{array}{c}\text { Priorit } \\
\mathrm{y}\end{array}$ \\
\hline 1 & CBTC system & $\begin{array}{l}100 \mathrm{kbps} \\
\text { for each } \\
\text { train }\end{array}$ & $\begin{array}{c}100 \mathrm{kbps} \text { for } \\
\text { each train }\end{array}$ & $<150$ & $<150$ & $\begin{array}{l}\text { Main line, exit } \\
\text { section/field rine, } \\
\text { section/field throat } \\
\text { area, section/field } \\
\text { garage, test line }\end{array}$ & 1 \\
\hline 2 & $\begin{array}{l}\text { Train } \\
\text { operation } \\
\text { status } \\
\text { monitoring }\end{array}$ & $100 \mathrm{kbps}$ & & $<150$ & $<150$ & $\begin{array}{l}\text { Main line, section/field } \\
\text { parking checklist }\end{array}$ & 2 \\
\hline 3 & $\begin{array}{l}\text { CCTV } \\
\text { surveillance } \\
\text { cabinet image } \\
\text { return }\end{array}$ & 4 Mbps & & & $<300$ & $\begin{array}{l}\text { Stop line, segment/field } \\
\text { parking checklist }\end{array}$ & 2 \\
\hline 4 & $\begin{array}{l}\text { Ns video (with } \\
\text { urgent text) }\end{array}$ & & $4 \mathrm{Mbps}$ & & $<300$ & $\begin{array}{l}\text { Main line, section/field } \\
\text { parking checklist }\end{array}$ & 4 \\
\hline Total & & $5 \mathrm{Mbps}$ & $5 \mathrm{Mbps}$ & & & & \\
\hline
\end{tabular}

\section{Analysis of LTE Bearer Technology for Vehicle and Ground Communication Integrated Service}

LTE is a global standard developed by $3 \mathrm{GPP}$ and is deployed in $20 \mathrm{MHz}$ bandwidth. In the case of single antenna transmission, the peak rate can be up to $100 \mathrm{Mbps}$ and the uplink can reach $50 \mathrm{Mbps}$. At the same time, LTE adopts a flat network architecture to reduce the control plane and user plane delay, and adopts advanced technologies such as OFDM (Orthogonal Frequency Division Multiplexing), MIMO (Multiple People Multiple Output), and HARQ (Hybrid Automatic Repeat Request). These effectively increase data rate, spectral efficiency and interference immunity. It also provides priority scheduling and high-speed mobility support for integrated service bearers, and secure and reliable transmission of wireless data services through anti-jamming technology and security mechanisms ${ }^{[7]}$.

TD-LTE is a TDD (Time Division Multiplex) version of LTE technology. It is also a $4 \mathrm{G}$ international communication standard technology with core intellectual property rights in China. It is a wireless communication standard designed for mobile high-bandwidth applications. The Ministry of Industry and Information Technology has issued TD-LTE licenses to three operators at the end of 2013. From the current commercial situation of TD-LTE networks, the industrial status of TD-LTE networks has matured, and performance indicators such as network coverage, continuous coverage and handover have reached the expected requirements.

\section{Qos Guarantee for Integrated Services}

The LTE system defines nine QCIs (Quality of Service Class Identifiers) according to the predefined types of possible bearer services, corresponding to different quality of service (delay, packet loss, etc.) ${ }^{[8]}$, as shown in Table 2. The system performs resource allocation and scheduling according to the priority corresponding to the QCI. The smaller the priority, the priority is to ensure resource allocation 
and scheduling.

Table 2 Classification of LTE Service Priority

\begin{tabular}{|c|c|c|c|c|c|}
\hline QCI & $\begin{array}{l}\text { Type of } \\
\text { resources }\end{array}$ & $\begin{array}{l}\text { Priori } \\
\text { ty }\end{array}$ & $\begin{array}{l}\text { i Packet data } \\
\text { delay / ms }\end{array}$ & $\begin{array}{l}\text { Packet data } \\
\text { loss rate }\end{array}$ & Examples of business \\
\hline 1 & & 2 & 100 & $10^{-2}$ & Voice service, cluster service \\
\hline 2 & $\begin{array}{l}\text { GBR (with } \\
\text { rate } \\
\text { guarantee } \\
\text { type) }\end{array}$ & 4 & 150 & $10^{-3}$ & $\begin{array}{l}\text { Call video service, video surveillance with rate } \\
\text { guarantee }\end{array}$ \\
\hline 3 & & 3 & 50 & $10^{-6}$ & $\begin{array}{l}\text { Real-time games, real-time online interactive } \\
\text { services, }\end{array}$ \\
\hline 4 & & 5 & 300 & $10^{-6}$ & Buffered streaming service \\
\hline 5 & & 1 & 100 & $10^{-6}$ & IMS signaling \\
\hline 6 & & 6 & 300 & $10^{-6}$ & $\begin{array}{l}\text { Video service (buffer streaming media), video } \\
\text { surveillance service without fixed speed book, FTP, } \\
\text { P2P, etc. }\end{array}$ \\
\hline 7 & $\begin{array}{l}\text { Non-GBK(n } \\
\text { on-rate } \\
\text { guarantee } \\
\text { type })\end{array}$ & 7 & 100 & $10^{-3}$ & General data service \\
\hline 8 & & 8 & 300 & $10^{-6}$ & FTP, P2P, etc. \\
\hline 9 & & 9 & & & Shared \\
\hline
\end{tabular}

\section{High-speed Mobility Support}

LTE supports terminal movement speeds of $350 \mathrm{~km} / \mathrm{h}$ (and even $500 \mathrm{~km} / \mathrm{h}$ in some bands) ${ }^{[9]}$.

For mobile communication systems, when the speed of the mobile terminal reaches $200 \mathrm{~km} / \mathrm{h}$ or more, the influence of the Doppler shift effect needs to be considered. LTE has been considered in design, and the base station side receiver uses AFC (Automatic Frequency Control) for frequency correction. AFC improves the demodulation performance by quickly measuring the frequency offset caused by idle motion, compensating for the Doppler effect, and improving the stability of the wireless link.

\section{Security Mechanism}

The security risks of wireless networks mainly come from malicious access and interception of wireless air interfaces. When accessing the LTE wireless network, the terminal UE must first authenticate and authenticate through the LTE wireless core network to prevent the terminal authorized terminal from entering the network and the unauthorized network receiving terminal to access the terminal. In addition, LTE uses AES (high-level encryption standard), SNOW-3G or Zu Chongzhi algorithm to encrypt and protect data, supports 128-bit dynamic password, and effectively prevents data from being stolen and tampered ${ }^{[10]}$.

\section{Anti-interference Technology}

The LTE network adopts a dedicated frequency band. For the same-frequency interference existing in the system, LTE adopts ICIC (Inter-Cell Interference Coordination) technology to perform interference coordination between cells. IRC (Interference Rejection Combining) technology is used 
for interference cancellation [11], which effectively improves the service rate and user experience at the cell edge.

\section{Vehicle-to-ground Wireless Communication Integrated Service Bearer Solution}

\section{Network Architecture}

Urban rail transit vehicle wireless broadband network based on TD-LTE technology, mainly carries CBTC system, train operation status monitoring system, CCTV and PIS system information transmission. The network supports future service expansion and can carry other services such as voice scheduling and train maintenance.

The overall logical architecture of the network is divided into three parts: the core layer, the access layer, and the terminal layer ${ }^{[12]}$, as shown in Figure 1.

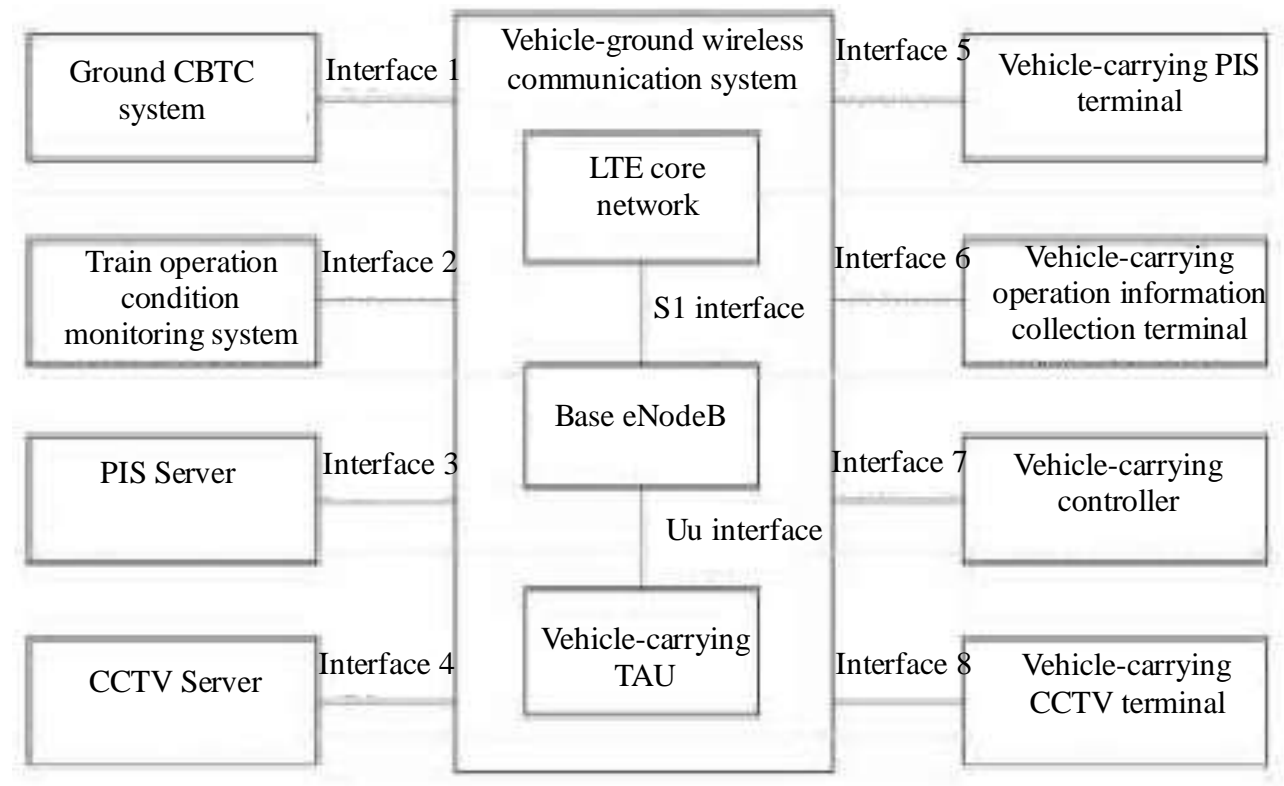

Figure 1 Overall Logical Architecture of LTE Integrated Bearer

The core subsystem: it is a key part of the entire wireless network, completes the aggregation and distribution of wireless transmission data, interconnects with other business subsystems, and provides them with reliable two-way data communication services. All wireless access data needs to communicate with external systems through the core layer. The core subsystem is also responsible for the management and maintenance of the entire network.

Access subsystem: It provides wireless access service along the track, and connect to the ground wired network on the uplink, and connect with the central subsystem to complete data transmission for various services.

In-vehicle wireless terminal: It consists of a vehicle-mounted wireless terminal, which is used to connect to the trackside wireless network to send and receive business information.

When using TD-LTE technology to construct a vehicle-to-ground wireless communication system, in order to enhance the security of the system, it is recommended to use A and B dual-network redundancy design. The two networks are completely independent and work in parallel without affecting each other. The A network is used for the bearer of the CBTC service alone, and the B network is used for the CBTC service backup and the train operation status monitoring, the PIS and the CCTV service bearer, and the two networks have the automatic switching function. When one of the networks fails, all services are automatically carried by another network. 


\section{Qos Planning}

According to the importance of the service and the transmission performance requirements, combined with LTE classification of priority and quality of service, as shown in Table 3, the priority and quality of service (delay, packet loss, etc.) of each vehicle communication service are defined.

The priority of the CBTC train control signal bearer service is set to 1 , which is the highest priority in the system. Since emergency information is issued under special demand conditions, it also requires higher priority, lower latency, and lower packet loss rate. The CCTV video surveillance backhaul of the train, and the PIS multimedia stream is defined as low priority.

Table 3 Business Priority and Quality of Service

\begin{tabular}{lcc|cc}
\hline \multicolumn{1}{c}{ Business Type } & \multicolumn{3}{c}{ QoS Setting } \\
\cline { 2 - 5 } & Priority & $\begin{array}{c}\text { Type of } \\
\text { resources }\end{array}$ & Data delay/ms & Data packet loss rate \\
\hline \multicolumn{1}{c}{ CBTC real-time data } & 1 & Non-GBR & 100 & $10^{-6}$ \\
$\begin{array}{l}\text { Emergency information text is } \\
\text { issued }\end{array}$ & 3 & GBR & 50 & $10^{-3}$ \\
$\begin{array}{l}\text { Information about the train's } \\
\text { real-time status }\end{array}$ & 4 & GBR & 150 & $10^{-5}$ \\
$\begin{array}{l}\text { Vehicle CCTV monitoring } \\
\quad \text { PIS streaming business }\end{array}$ & 4 & GBR & 150 & $10^{-3}$ \\
\hline
\end{tabular}

By dividing the non-N service into $\mathrm{N}$ priorities, the B BTC service transmission priority and quality of service (delay, packet loss, etc.) can be guaranteed, and then other services are scheduled for transmission.

\section{Scheme Verification}

The transmission performance and handover delay of TD-LTE have been extensively tested and proved in commercial communication systems, and can fully meet the transmission performance requirements of various production services of rail transit vehicle communication.

In order to verify the feasibility of the TD-LTE system in the urban rail transit vehicle wireless communication multi-service integrated bearer, and the adaptability of the signal systems of various manufacturers to the TD-LTE transmission channel, we have built a TD-LTE integrated system in Zhengzhou Metro Line 1. The service bears the test platform, and the scheme is shown in Figure 2. 


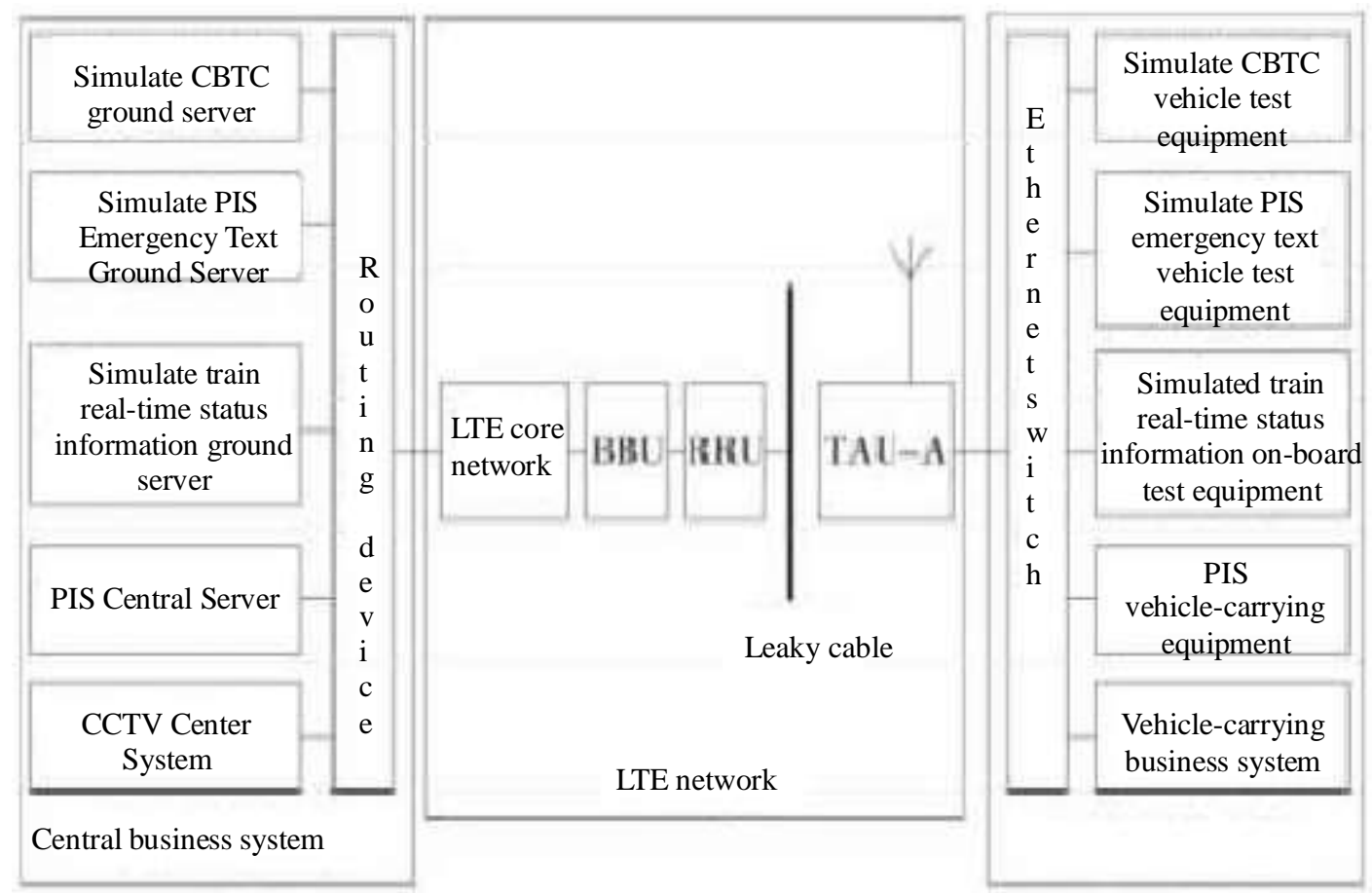

Figure 2 TD-LTE Network Integrated Service Test Scheme

For the sake of simplicity, a single-network system is used for the feasibility verification of the integrated service bearer, and the actual violation of the violation uses a dual-network redundant networking to improve reliability. A total of 24 BBUs, 67 RF remote units RRU and 50 in-vehicle wireless units TAU were deployed in the first phase of Zhengzhou Rail Transit Line 1. The main line tunnel is covered by the leaky cable, and the commercial communication system is leaky. The KKU combines the two signals with the frequency difference combiner and the commercial system to connect the two leaky cables for wireless coverage, special stations and vehicles. The lot is covered with omnidirectional and directional antennas.

In the business system, the CBTC business information and the real-time status information of the train use the analog mode to transmit and receive the business data, and the on-board CCTV surveillance image information and the PIS image information are transmitted and received by the real device.

During the test, the service simulator is used to generate 2 analog CBTC services, and 1 train status information service is listed as the highest priority: Under the condition of $15 \mathrm{M}$ bandwidth, $20 \mathrm{~W}$ transmit power, and uplink and downlink subframe ratio of 2: 2, upload two CCTV video surveillance at a rate of $2 \times 2 \mathrm{Mbps}$ : downlink distribution of one PIS video at a rate of $6 \mathrm{Mbps}$, using service simulation The device generates 1 emergency text service. The bearer test results are as follows.

(1) CBTC Business Test

When the train speed is maintained at $20,40,60 \mathrm{~km} / \mathrm{h}$, the CBTC service data test is carried out. CBTC can see the normal data service flow without packet loss.

(2) Upside Train Video Surveillance Test

The uplink service is repeatedly tested for pulling the network, and the in-vehicle video surveillance of the driving is taken at the OCC control center. The video capture rate is $2.0 \mathrm{Mbps}$, the video is smooth and clear, and multiple channels of video can be simultaneously captured, keeping the process clear and smooth during the pulling process. .

(3) Up and Down Video Concurrent Test

The car is verified by the network, and the whole line is tested and concurrently sent. The downlink 
is controlled by the control center to broadcast the $6 \mathrm{Mbps}$ high-definition source to the whole network. The uplink control also captures the in-vehicle video surveillance 1-3. The vehicle speeds were maintained at 20,40, and $60 \mathrm{~km} / \mathrm{h}$, respectively. The test showed that the uplink video surveillance and downlink video were played smoothly and without mosaic in the entire pull network test.

The same test was performed by reducing the TD-LTE bandwidth to $10 \mathrm{MHz}$, and other conditions such as power. The results show that the CBTC service is normal and there is no packet loss. The downlink 6 Mbps video playback is smooth and uplink. At the same time, in the case of two-way monitoring, there are pauses and mosaics in the process of pulling the net, and the playback is basically smooth when the 1 channel is monitored. Keep the bandwidth of $10 \mathrm{MHz}$ and change the ratio of the uplink and downlink subframes to 3:1. The test result of the pull network shows that the high-priority CBTC service is normal without packet loss, and the uplink 2-way video surveillance and downlink HD video playback are smooth, basically no mosaic.

Further reduce the bandwidth to $5 \mathrm{MHz}$, and the uplink and downlink subframe ratio is 2: 2. The test shows that the high-priority CBTC service has no packet loss, but the uplink and downlink video playback has mosaic phenomenon, especially in the border area of the adjacent KRU coverage, the video cannot be played normally.

The comprehensive test results show that the network signal coverage is good and the bandwidth is not less than $10 \mathrm{MHz}$. By setting the appropriate uplink-downlink ratio, TD-LTE can meet the requirements of CBTC, train operation status monitoring, 2-channel CCTV monitoring, and PIS video. When the bandwidth is further reduced, the bearer rate of the network will not be sufficient to meet the requirements of video surveillance and video delivery. Therefore, it is recommended to use TD-LTE to carry out the vehicle-to-ground communication integrated service bearer. It is necessary to ensure the bandwidth above $10 \mathrm{MHz}$ and set the uplink-downlink subframe ratio according to the uplink and downlink service requirements to meet the multi-service bearer bandwidth requirements.

Dynamic bandwidth allocation technology is a key technology in EPON technology. Since EPON technology uses Time Division Multiplexing (TDMA) technology in the uplink, only one ONU can communicate in each time slot. In order to make full use of the bandwidth, the OLT dynamically adjusts the bandwidth allocation according to the data transmission $\mathrm{M}$ of the ONU, and allocates a longer time slot to the ONU with the largest upload data, thereby obtaining a larger bandwidth ${ }^{[12]}$. This technology works very well in the access network because the randomness of the uplink data of the user in the access network is strong, and the probability that the user needs a large uplink bandwidth at the same time is very low.

However, in the video surveillance system, it is necessary to maintain real-time viewing of all video monitoring points. Since the video stream of the camera is not the same, the amount of data will be multiplied when the picture changes ${ }^{[13]}$. If a camera first applies to the OLT to increase the bandwidth, the video stream bandwidth of other cameras will be invaded and appear to be stuck. Therefore, in the video surveillance system, the bandwidth allocation strategy should be changed from dynamic bandwidth allocation to fixed bandwidth allocation to adapt to the characteristics of the video surveillance system.

\section{Conclusion}

Taking the video surveillance system of the Wuxi Marshalling Station as an example, this paper describes how to use the EPON technology to build a video surveillance system in a large field $\mathrm{K}$, and compare it with the traditional networking method, and finally draws conclusions. EPON technology is used to set up a video surveillance system, which not only has low construction cost, good network scalability, and strong network management capability, and has no active devices between the side and the user side, few fault points, easy maintenance, and strong anti-electromagnetic interference performance. It has become an excellent solution for setting up a video surveillance system for 
large-scale venues.

Video surveillance systems have become an indispensable means of safe production and anti-terrorism and anti-riot in railway operations. With the development of information technology, the video surveillance system itself has been continuously updated. How to find a video surveillance system that is more suitable for railway construction will become the direction that railway designers will continue to explore in the future.

\section{References}

[1] Bai Fan. Application of Video Surveillance System in Railway Construction[J].Journal of Lanzhou Jiaotong University,2012.31(S):138440.

[2] Liu Silun. Application of Ground Source Heat Pump in Metro Station in Hot Summer and Cold Winter Areas [D]. [D]. Wuhan: Wuhan University of Technology, 2014

[3] Li Chao. Analysis of Bamboo Energy Design for Subway Power System[J].Railway Construction Technology, 2010, (Supplement): 148-152Bai Jianbin. Establishing Next Generation Cable TV Network with EPON Technology[J]. Railway Communication Signal, 2008, 44(10): 40-42.

[4] Hong Weipeng, Sun Yaobo. Application Research of EPON Technology in Highway Video Surveillance System[J].Highway.2010(I):102-105.

[5] Zheng Xunlei. Talking about the Research of KPON Network Construction Scheme Railway Communication Signal, 2008, 44 (12): 56-58.

[6] Shan Chaoyang. Jiao Heyong, Chen Xing. Design of Park Network Video Surveillance System Based on EPON Technology[J]. Technology and Applications, 2014(2): 77-82.

[7] Chen Xiaolin, Ye Lixu. Design and Implementation of Video Monitoring System for Ningbo Rail Transit Construction Network[J].Railway Standard Design,2009(12):130-133.

[8] Xie Guiyue, Xie Peirong. Communication Line Engineering Design [M]. Beijing: People's Posts and Telecommunications Press, 2008.

[9] Xie Guiyue. Chen Xiong, Zeng Ying. Cable Transmission Communication Engineering Design [M]. Beijing: People's Posts and Telecommunications Press, 2010.

[10]Wang Wenjie. Experience in KPON Network in Video Surveillance System [J]. Internet of Things Technology, 2014(4): 18-20. 